\title{
Resilience and Career Counseling: Describing the Utility of Quadrant Mapping
}

\author{
Liesel Ebersöhn \\ University of Pretoria
}

Please address all correspondence to Professor Liesel Ebersöhn, Department of Educational Psychology \&, Unit for Education Research in AIDS, Faculty of Education, University of Pretoria, 0002, Pretoria, South Africa. E-mail: liesel.ebersohn@up.ac.za

This article describes the manner in which educational psychology students ( $\mathrm{n}=11$ females) used quadrant mapping when doing career counseling with Grade 9 youths $(n=88,47=$ male, $41=$ female) in a rural secondary school in South Africa. Quadrant mapping involves a depiction of measured intrapersonal and environmental risk factors and protective resources. The qualitative case study generated data which was based on individual interviews with students during four intervals (documented in field notes), observations of educational psychology interventions by students (documented in field notes), and students' intervention planning and reflections (recorded in reflective diaries). Students facilitated the interventions (in the form of educational psychology assessment and intervention sessions) with the participating youth. Data was thematically analysed. Students either used postmodern approaches exclusively, or combined postmodern approaches with adapted existing career counseling measures for quadrant mapping. Quadrant mapping is useful for cross-cultural career counseling, establishing assets in resource-scarce settings, as well as for use with groups and in schools.

Keywords: quadrant mapping, asset-focused resilience, risk factors, protective resources, postmodern career counseling, cross-cultural career counseling, resource-scarce settings

As most South African youth can be viewed as vulnerable ${ }^{1}$ (Amon, 2002; Booysen \& Arntz, 2002), providing career counseling (amongst other educational psychology services) for vast numbers of potentially at-risk youth remains an issue. The hardships faced by the youth take the form of environmental risk factors, such as poverty, the need to take care of family members incapacitated as a result of HIV\&AIDS-related illnesses, problems with learning resulting from the fact that the language of teaching and learning differs from their mother tongue, and attrition partly resulting from teenage pregnancies (Brookes, Shisana, \& Richter, 2004; Cluver \& Gardner, 2006). This cumulative risk requires health professionals to provide youths with functional tools for designing lives that demonstrate resilience (Bray, 2003; Cluver, Gardner, \& Operario, 2007). Although there is policy in place that prescribes school-based services to assist such vulnerable youth, most school going youths are not refered for educational psychology services (Bennell, 2005; Bennell, Hyde, \& Swainson, 2002). Career counseling in cumulative risk contexts could assist clients in answering the following question when scripting their lives: What can I do with what I have to address barriers and live a life in which I can thrive and be happy? A related query would be to determine certain techniques to facilitate such resilience-oriented career counseling.

\section{Methods in Career Counseling}

Much has been written on appropriate methods of measurement in career guidance, including validated measures (McMahon \& Patton, 2002; Savickas, 2007; Thrift \& Amundson, 2005) and the indigenisation of measures (Adair, Puhan, \& Vohra, 1993; Maree, Bester, Lubbe, \& Beck, 2001; Stead \& Watson, 1998). Scholars also seek to understand how quality career counseling can be made accessible to vast numbers of citizens in countries with emerging economies (Savickas, 2003;
Watson \& MacMahon, 2004). Similarly, many studies have indicated the need to understand better the assessment of resilience relevant to counseling (Keyes, 2007; Lopez et al., 2006; Smith, 2006). Use of qualitative and postmodern approaches could address these issues. In this paper I describe the utility of one qualitative, postmodern technique, namely quadrant mapping, ${ }^{2}$ in providing career counseling for vulnerable youth in an isolated, rural school in order to enable them to design their lives independently so as to manifest resilience.

Against the background of this argument, the following question directs this article: What is the utility of quadrant mapping to measure risk factors and protective resources in career counseling in order to facilitate resilience? This question resulted from an ongoing qualitative study in a rural secondary school in South Africa. In this article I describe the way in which educational psychology students used quadrant mapping during an academic service learning ${ }^{3}$ activity to provide career counseling to a vulnerable group of Grade 9 youth. The theoretical framework for this study is that of asset-focused resilience (Ebersöhn, 2008).

\section{Contextualisation}

This study forms part of FLY (Flourishing, Learning Youth), which is an ongoing partnership (2006-present) between the Department of Educational Psychology at the University of Pretoria and a deep rural South African secondary school. FLY constitutes an academic service learning practicum (Bender, 2008) during which career counseling is investigated in terms of a resilience framework. Career counseling from a resilience framework means that it is seen as a vehicle for enabling clients to make use of their existing resources to not only address barriers, but also, more notably, to be able to thrive in their lives. Drawing on resilience framework concepts (e.g., Bonanno, 
2004; Carver \& Scheier, 2005; Cluver \& Gardner, 2007), Flourishing Learning Youth (FLY) denotes resilience as adaptive functioning behaviour that enables one to bounce back from adversity (signified by risk factors) by harnessing available protective resources.

Flourishing Learning Youth. In FLY the intricacy of matching career counseling measures with a specific population is a challenge. Participants in FLY include two groupings. One group comprises postgraduate students who provide the youth with educational psychology assessment and intervention services as part of their academic service learning practicum. Although the students are heterogeneous ${ }^{4}$ they are predominantly female, white and Afrikaans or English speaking. The other group consist of Grade 11 learners (boys and girls ranging in ages from 15 to 18 years) from predominantly siSwati and isiZulu cultural groupings. Most existing career guidance measures are validated for specific ages and cultural groups demographically dissimilar to the youth group concerned. As a result, since the start of FLY, most students have used various postmodern, qualitative measures in their interaction with the youth to better bridge the cultural divide with the school learners. These measures have proven to be culturally adaptable (Brandt, 2005) as they mediate the negative effects of language, cultural and contextual diversities between the postgraduate students and the Grade 11 youth. Accordingly, one of FLY's goals was to develop and pilot quadrant mapping as an indigenous psychology measure in career counseling.

Asset-Focused Resilience and Career Counseling. The notion of resilience holds significant promise in career counseling (Schreuder \& Coetzee, 2006), as issues of resilience come to the fore in cases where individuals need to address adversity. Asset-focused resilience posits that resources coexist with adversity (Ebersöhn, 2008) and the coexistence of risk and protection signals mutuality. Significantly, in terms of an asset-focused resilience framework, the emphasis is placed on the presence of resources. The intention of this strengths-focus is to harness positive psychology constructs, including hope, optimism and expectancy to address adversity. Asset-focused resilience is premised on the assumption that the available assets can be used to address the identified risks - enabling the individuals to flourish. As in other resilience theories (Fredrickson \& Losada, 2005; O'Dougherty Wright \& Masten, 2006), asset-focused resilience resources refer to both personal and environmental strengths which act as buffers in order to counter risk. Likewise, in adversity, asset-focused resilience forms a compound buffer to the risk factors individuals face in their personal and environmental systems. Asset-focused resilience to career counseling implies the identification, or measurement, of both risk factors and protective resources in clients' lives. Career counseling based on asset-focused resilience aims at raising clients' awareness of measured barriers and buffers. The underlying principle used during career counseling is for professionals to be functional in enabling clients to understand how they can write a libretto for their lives in which they use the available assets resiliently as buffers to address the identified risks.

\section{The Quadrant Mapping Approach}

It is apparent from the above discussion that, "[e]ven though lack/scarcity/flaws/shortcomings do not constitute the central focus of asset-focused [resilience], they constitute elements of the backdrop of the intervention process" (Ebersöhn \& Eloff, 2006). As a result, a quadrant can illustrate the challenges and dynamics related to a multiplicity of risk and protection in an individual's life. Figure 1 gives a picture of a generic quadrant map.

Measured risk factors and protective resources can be displayed in a quadrant map. Measurements can include: (i) a pen-and-paper exercise where clients are asked to write in examples of perceived strengths and barriers in quadrant spaces; (ii) an interview, where the professional formulates the focus of each quadrant as a question and notes the client's responses in the relevant quadrant spaces; or (iii) information for the quadrant spaces, which can be derived from other activities, the outcome of which is mapped by the professional in a quadrant.

Whichever way followed to construct it, quadrant mapping reflects self-reported sources for adaptive functioning behaviour (resilience) in terms of context. A quadrant map can serve as a potential framework on which the clients can plot strategies when designing their lives. A career counseling discussion based on a quadrant map can indicate to a client how he or she can identify potential risk factors and protective resources in their own lives during times of adversity. In the same way, clients may come to realise that the top quadrants provide them with the capital to cope with the problems depicted in the lower quadrants. Similarly, during career counseling, clients can learn to plot their assets and risks onto quadrants themselves in order to devise strategies for addressing future adversity independently in the absence of professionals.
Person

Protective signature strengths; gifts (e.g., caring,

resources healthy, likes drawing)

Risk factors Deficiencies; challenging characteristics (e.g., bereaved, withdrawn, rebellious, hungry, learning disability)

Environment

Assets; resources; opportunities (e.g., availability of childcare grant, home-based care visits, after school activities)

Lack; destructive factors (e.g., orphan, child-headed household, illiterate parents unable to help with homework)

Person

Environment

Figure 1. A generic quadrant map. Adapted with permission from "Life skills and assets (2nd ed.)," by L. Ebersöhn and I. Eloff (2006). Copyright 2006 by Van Schaik Publishers. 
Table 1

Participants

\begin{tabular}{|c|c|c|c|c|c|c|}
\hline & Student & $\begin{array}{c}\text { Total } \\
\text { in group }\end{array}$ & Boys & Girls & $\begin{array}{c}\text { Mixed } \\
\text { gender group }\end{array}$ & $\begin{array}{c}\text { Same } \\
\text { gender group }\end{array}$ \\
\hline & $A$ & 9 & 5 & 4 & 1 & 0 \\
\hline & $B$ & 8 & 8 & 0 & 0 & 1 \\
\hline & $\mathrm{C}$ & 8 & 0 & 8 & 0 & 1 \\
\hline & $D$ & 6 & 6 & 0 & 0 & 1 \\
\hline & $E$ & 10 & 6 & 4 & 1 & 0 \\
\hline & $\mathrm{F}$ & 8 & 8 & 0 & 0 & 1 \\
\hline & $\mathrm{G}$ & 6 & 6 & 0 & 0 & 1 \\
\hline & $\mathrm{H}$ & 8 & 8 & 0 & 0 & 1 \\
\hline & I & 9 & 0 & 9 & 0 & 1 \\
\hline & $J$ & 8 & 0 & 8 & 0 & 1 \\
\hline & $\mathrm{K}$ & 8 & 0 & 8 & 0 & 1 \\
\hline TOTAL & 11 & 88 & 47 & 41 & 2 & 9 \\
\hline
\end{tabular}

\section{Goal of the Study}

The goal of this study was to explore the utility of quadrant mapping as postmodern technique in career counseling, with the following research question directing the study: What is the utility of quadrant mapping in postmodern, cross-cultural career counseling?

\section{Method}

\section{Participants, Setting and Research Design}

Participant characteristics were as in Table 1. In the first instance 11 ( $n=11 ; 11$ female; 10 Afrikaans-speaking Christian; 1 English-speaking Muslim) postgraduate educational psychology students were selected based on the following criteria: they had participated in the 2009 academic service learning activity in the FLY programme, they had used quadrant mapping during career counseling, and they had developed quadrant maps as a career counseling feedback instrument for youth. The second group consisted of 88 Grade 9 youths $(n=88,47=$ male, $41=$ female). The selection of the youths was based on two criteria: they were in Grade 9 in the specific secondary school and they had participated in the FLY educational psychology intervention.

Baseline information on the school community indicates the following characteristics (Ebersöhn, 2006): The rural school is situated in a low-income and primarily subsistence agricultural economy area. Most of the adults in the community are illiterate. HIV\&AIDS-related illnesses and deaths are prevalent. Many households are headed by children, or the children live with caregivers other than their parents. The extremes of poverty have led to schools providing their learners with food through a overnment-funded feeding programme. The language of teaching and learning in the school is English, although the mother tongue of the majority of teachers and youth is isizulu. Both youth and teachers travel vast distances (the youth on foot) to attend the school. Many of the youth have secondary roles to perform as caregivers in their homes (both for siblings or ailing adults), meaning that they have multiple chores to do in the mornings before, and in the afternoons after, school. For these reasons the school does not provide after-school care or activities.
As is evident from Table 1, each student worked with a group of youths and the youths themselves decided who they wanted to be grouped with. As a result the groups were heterogeneous - most of the groups (9) consisted of a single sex, with two comprising both sexes, and the group size ranged from 6 to 10. In this specific school, youth in Grade 9 range from 15 to 18 in age.

\section{FLY Educational Psychology Career Counseling Intervention}

Paradigmatically this instrumental case study (Stake, 1995) followed a qualitative methodology from an interpretivist metatheory. Since 2005, every University of Pretoria MEd (Educational Psychology) student group has undertaken two two-day visits (three months apart) to the school annually in order to engage with Grade 9 youth. These activities are incorporated into the formal school year plan and take place on the school grounds during school hours. Each intervention day consists of four hours of educational psychology services. The first two-day visit focuses on educational psychology assessment, and the second on educational psychology counseling. These activities aim to enable the youth to address barriers (identified during assessment) and thrive in their career pathing (by using the resources identified during assessment). Students each develop their own interventions by deciding which approaches, techniques and activities they would like to implement. The students therefore develop new measures and activities, as well as making use of existing ones.

\section{Data Collection, Documentation and Analysis}

Interviews. Students were each interviewed on four separate occasions spanning both the assessment and the intervention phases: the planning phase of assessment sessions, the post-implementation of assessment, the planning phase of counseling sessions, and the post-implementation of counseling. The researcher conducted unstructured, face-to-face interviews with students as participants (based on the latter's career counseling with participating youth). The interviews were documented in field notes. Interventions were observed, and documented as photographs to crystallise insights into the data. However, these photographs were not taken into account as a data source for this article. 
Intervention observations. Interventions were observed and documented visually (photographs) and textually (field notes) to crystallise insights into the data. Only textual data were taken into account as an observation data source for this article.

Intervention planning and reflections. Students generated data in terms of assessment and intervention artefacts. Their intervention planning served as textual data and they documented their reflections on the intervention in their reflective diaries. All data sources were thematically analysed and then interpreted (Braun \& Clarke, 2006).

\section{Trustworthiness of the Research}

Credibility was obtained by being engaged in the field over an extended period (Seale, 2000), while dependability was achieved by constructing a chain of evidence from the collected data, as well as the research decisions and processes (textual data, reflective notes in diaries, field notes of interviews, visual data) (Seale, 2000). Authenticity and transferability resulting from crystallisation were assured by demonstrating various realities (students' reflective diaries, researcher's accounts in field notes, visual data). In addition, transferability was addressed by providing a rich description of the case and the participants.

Procedure. In this study the process was as follows: career counselors (students) plotted the youths' assessment information onto individual quadrant maps. During the group session the career counselors (students) distributed the individual quadrant maps to the youths. Next, the career counselor explained the principles underpinning the quadrant maps while the youth could refer to their own individual quadrant maps. The youth then asked questions regarding this explanation which the career counselor answered. Thereafter, the career counselor moved among the youth to clarify individually if needed.

\section{Ethical Considerations}

The students and youth provided informed consent to participate (Mauthner, 1997). In cases where the youth were minors informed assent was requested from parents/caregivers for their children to participate. As visual data of intervention artefacts and the intervention sessions were collected, participants were specifically consulted about visual recognition and the limitations related to anonymity and confidentiality. Accordingly, participants could opt not to be photographed. Owing to the vulnerability of the population, as well as the sensitive nature of educational psychology, a registered educational psychologist supervised the FLY interventions at the school in the event of adverse effects and each student was given a referral list of relevant teachers, social workers and faith-based leaders to whom they could refer in such circumstances. Students also provided their group of youth with their telephonic contact number.

\section{Scope and Limitations of the Study}

The study is limited to the demographic distinctiveness of a small number of female postgraduate students, as well as one group of youth, and is aimed at describing a case of quadrant mapping done by these participants in one particular rural school, without the intention of generalising the findings outside the framework of this study. By presenting descriptions of the case the likelihood exists that findings may be transferable to other comparable settings. I acknowledge that differences in language between the two distinct participant groupings may in some instances have caused a lack of clarity during mean- ing-making. Furthermore, exploring the youth's experiences of quadrant mapping could have added to additional insights.

\section{Results of the Study}

\section{Ways of Measuring Risk Factors and Protective Resources for Quadrant Mapping in Career Counseling}

Students opted to generate data for the quadrant maps by either (i) implementing qualitative, postmodern techniques, or (ii) combining existing measures with new postmodern techniques. Where students used existing career counseling measures they often adapted them by including isiZulu concepts to facilitate cross-cultural communication, and shortening a measure by limiting the variety of items the youths could choose from. Assessment activities were group-based, where students gave an instruction for an activity. Whilst the group engaged in the activities the students moved among individual group members to clarify meaning-making. In all of the groups one youth naturally came to the fore as a translator to mediate between the student and his or her peers. Significantly, students did not ask youth merely write risk factors and protective resources on a quadrant; or used quadrants as interview schedules.

Besides asset-mapping, students used the following qualitative and postmodern techniques to generate data on risk factors and protective resources: a range of interactive games to indicate preferences (used in particular to determine interests and personality traits) (Bachorowski \& Owen, 2001), lifelines (Patton, 2007), family trees, incomplete sentences, drawings (e.g., "draw a day in your life", "draw your community") (Backette-Milburn \& McKie, 1999), deconstructing early recollections (Chope \& Consoli, 2007), card sorts (Patton, 2007), sections of narrative career style interviews (Hartung, 2007), art activities (creating the community with paint, clay, sticks, or grasses and stones) and memory-boxes (Ebersöhn, 2007) to indicate the environmental factors (on the outside of the box) and intrapersonal factors (inside the box).

The following extract from a student's reflective diary on the assessment of a 15-year-old boy is an example of assessment results obtained from a combined measurement strategy:

In terms of interest, Tshepo 5 indicated on the "I would like to be" questionnaire ${ }^{6}$ that he has an interest in areas calculations, service, and scientific. In the "Card Sort" activity ${ }^{7}$ he indicated that he has a strong interest in areas such as outdoor, calculations and musical. Regarding his personality, ${ }^{8}$ Tshepo's results indicated that he has a good self-concept. $\mathrm{He}$ is an extrovert, optimist, enthusiastic, and a leader. He is motivated and can be busy with several different challenges at once. He may struggle with human relations and may be impatient, aggressive or insensitive, struggling to cope with other people who get angry easily. From incomplete sentences it seems that emotionally, Tshepo feels that he has a negative effect on people and that they perceive him as dangerous. He does however feel that he has an important function to fulfil. In the asset-map he indicates that his teacher is very important in his support network, as well as his family. Tshepo's mother died, however based on the organogram it seems that he still has his father, grandparents and a sister, who currently lives with her mother. He mentioned that he has a very good friend that is very supportive and important to him. Regarding relationships, Tshepo showed strong feelings for his family. He indicated that his mother passed away, and that he finds support from his brother and father, indicated by the gold strand cowering 
over him. He also indicated that his own life is important to him, in that he indicated himself symbolically in his future picture. ${ }^{9}$ Based on depictions in his drawings of children who are HIV positive, as well as the teenagers who have to take care of themselves Tshepo indicated HIVIAIDS as a presence in his life. Tshepo lost his mother, and he is still finding it hard to cope on his own, although he has the support of his father and brother. He may have fears of HIVIAIDS for himself, due to his mother's death. His drawings indicated basic uncertainty, rigidness and being under pressure. He indicates desires to move forward and strong family relations. Dependency, problems with interpersonal relations and feelings due to the loss of his mother are present.

This extract indicates that students co-constructed assessment results with the youth based on both postmodern and existing career counseling measures. Following the analysis and interpretation of the assessment data, students drew up quadrant maps based on the assessment results similar to those presented in the reflective diary extract above. The following section describes the ways in which the students extricated information on risk factors and protective resources from the assessment results for the purpose of quadrant mapping.

\section{Varied Depictions of Quadrant Maps as Outcome of Measurement}

Students were all able to depict risk factors and protective resources in quadrant maps. These depictions ranged from simplistic (refer to Figure 2) to complex (see Figure 3). However, in most cases the quadrant maps were similar to that reflected in Figure 4, providing key information about the buffers and barriers in a specific youth's life.

No clear pattern emerged for types of quadrant map based on the career counseling assessment approach. The level of intricacy in the quadrant maps varied irrespective of whether the students used an exclusively postmodern assessment approach in getting to know the youth (refer to Figures 2 and 3), or combined existing and postmodern techniques (refer to Figure 4).

\section{Students' Reflections on the Use of Quadrant Maps in Designing a Resilient Life}

The students used quadrant maps as a framework to guide their career counseling discussions with the youth. A vignette from one of the student's reflective diary (translated from Afrikaans) indicates her learning experience during the use of quadrant maps. This vignette serves as an example of the way students used quadrant maps to structure their analysis and interpretation of the career counseling assessment data:

It was rather difficult for me to make quadrant maps. I took the activities, analysed them, looked at the analysis, espe- cially at the most important information that I could get from it. That directed me to the general themes to focus on during the intervention, but then I also had to use the information in a way that I could represent it on a quadrant map for each child. As I mentioned, I know quite a bit about the theory of asset-maps, but l've never used them in practice. We made a map for another assignment, but only to complete a report, not to really to make use of the map. This was therefore my first experience in making and using a quadrant map. To compile the quadrant map before the counseling visit I took the media and that which I saw therein and wrote this on the asset-map.... I also tried to see if it made sense to use the assets to bridge the barriers, because that is the reason for compiling the quadrant map. I was quite surprised by how many assets I could identify.... I like the use of a quadrant map, because it doesn't deny the existence of barriers, but gives guidance about how barriers can be overcome through assets, and how assets can be used to compensate for barriers.

Quadrant maps enable students to guide career counseling sessions with youths, as is evident from the following reflection: "It gave me a holistic picture of the client and I could easily consult information about strengths and challenges. I like that everything is on one page, which makes my conceptualisation of each client easier." Using quadrant maps students were able to foreground strengths in a resource-scarce environment which they could then bring to the attention of youth, as one student notes: “... after I drew up the children's quadrant maps and wrote their reports, I did not feel pity for them anymore, but rather a kind of excitement to present them with their quadrant maps and introduce them to the other side of the "pity continuum'."

Participant students stated that the use of quadrant maps recognized the presence of the harsh realities that the youth needed to cope. In fact, students used the quadrant maps to generate future strategies with the youth showing them how resources could be harnessed to design a life that addresses needs optimistically, as is apparent from the following student's reflection: "I want to leave (the youth) with the thought that they have special and different gifts ..., and assist them to realise how they can use these gifts and strengths for their future."

The following student's reflection indicates strategies used with a youth as a way to use identified buffers to address identified barriers:

Londiwe $^{10}$ and her family struggles financially, lacks physical resources and she often expressed that she was hungry. She views her family, the school, church, shops, a road and cultivated land as environmental assets. She expressed the need to "move freely" like a dog that can run around. She has the ability to think abstractly and has a strong personal-

\begin{tabular}{lll}
\hline & Individual & Environment \\
\hline Asset & organisational skills, a team-player and collaborator & older siblings to assist and support him \\
& hopeful and optimistic approach to life & older siblings staying in cities who may act as a \\
& high aspirations for himself & financial resource at a later stage \\
Barrier & low academic performance & limited emotional support in home environment \\
\hline
\end{tabular}

Figure 2. Simple quadrant map of a 16-year-old boy resulting from combined measurement 
Individual

MY STRENGTHS (Wami amandla)

don't give up, caring, creative, funny, loving friend, laughs, connect people, singing, happiness, reading, going places, dreams - president, own business, positive, leader, goals, supporter, respectful, listen, hard worker, good heart, creative, likes writing poems, big expectations, well behaved, intelligent, wants to give back to the community, insightful, religious, open to guidance and mediation

\section{MY LIMITATIONS}

lack self-knowledge, limited self-believe, no idea how beautiful and talented she is, diligence regarding homework, can get "gloomy"
Environment

MY BUFFERS (Wami londa)

individual assets:

family support (especially mother - nurse)

accommodation, homework assistance, food, clothes, friends: love. cultural heritage. subject-teachers, administration staff. support: teachers (counseling) school \& physical assets: school buildings \& offices, electricity, library, office-based equipment, spaza/tuck shop, classrooms, tables, chairs, books, computer training, running water, sanitation / toilets, playground, sport facilities, posters, counseling centre, school activities, school uniforms, own vegetable garden, feeding scheme, DSTV-facilities, transport (e.g., bus), parental involvement (e.g., making food)

assets within the closer community: beauty of surroundings, churches, clinic, shops \& local businesses, fertile ground, tourism centres, mayflower centre, animals, natural recourses, river bed, wood, other schools, municipality (services \& careers) involvement of organisations (e.g., Nestlé) transport for resource deliveries

\section{THE BARRIERS}

individual barriers:

limited emotional support, lack of financial support, effect of unemployment of father, bullying/intimidation, illness mother

school \& physical barriers:

droughts, litter, lack of electricity in all classrooms, lack of departmental support/resources, fighting, drugs, bathroom facilities, waste of water, decayed buildings (e.g., holes in ceilings), alcohol, inappropriate graffiti, lack of finances, unused resources (e.g., chairs, books \& posters)

barriers within the closer community:

alcohol, drugs, droughts, scarcity of jobs, pollution, remote location, crime, low socio economic environment

Figure 3. Complex quadrant map of a 15-year-old girl resulting from postmodern measurement

ity (although she might appear arrogant/overpowering). She is committed to learn (school engagement, homework and reading for pleasure), likes dancing, makes good decisions, is keen to organise and plan, has social competencies (interpersonal skills, conflict resolution and wanting to help people), a positive self-concept (in terms of a tree, she sees herself as strong, powerful, creative and bearing many fruits and flowers) and is able to read and understand English (although she battles to speak in English). Her favourite subjects are social and natural sciences, as well as SiSwati and English. The main career fields which interest her are scientific (medical) and social service (recreational, education, physical). She is adamant that girls should not be sexually active because she does not want to fall pregnant.

Maybe by helping her to connect the idea of freedom with ... the expression of talents and who she is, might help her overcome the idea that she is not free to do as she wishes due to a lack of physical resources. Londiwe might benefit from starting a group with a specific purpose either at school or at church (it might be a support group for discovering and mobilising talents, a dance group, a reading group, a lan- guage group). Her ability to speak in English may be improved if she starts an English reading group where peers take turns to read out loud. Londiwe's strong opinion on sexual activity among teenagers could also serve as a launch pad for her to start a support group where girls can help one another to make responsible choices. We can talk about a plan of action to establish and maintain such a group. Her preference for languages is a resource for confidence in public speaking which could fit her strong leadership abilities. She might also feel enabled in a leadership position at school. I will share with her how to volunteer for specific school duties in this regard. Her subject preference for languages is a resource for confidence in public speaking which could fit her strong leadership abilities and need to help others. I will speak to the guidance teacher to see if she may have another helping of food from the nutrition programme during break time. As she has limited access to financial resources I will stress the fact that academic achievement may result in bursaries for tertiary education. Higher academic achievement is plausible as she is committed to learning and already achieves in some subjects. I 
Individual assets

finds his own life very important to himself

extrovert

very optimistic

good leader

feels he has an important role to fulfil, can handle pressure, and several tasks at once,

finds positive support from one specific teacher and his family

has one very good friend who is very supportive

cares deeply for others, awareness of HIV/AIDS, through

acknowledging the children who have HIV/AIDS, as well as the

teenagers who have to look after themselves

longs for a bright future

focused on success and achievement

feels he has a negative effect on people and that they perceive

him as a negative influence

negative self-concept

his mother died

struggles to cope after his mother's death

fears of having HIV/AIDS himself

impatient

may not always be aware of the feelings of others

may struggle with human relations

may be disrespectful to others

feels the community has a misconception of who he is

experiences himself in isolation from the community and others

struggles with social relations

uncertainty

dependency

busy removing himself from everyone around him
Buffers in environment

school that is close to home,

educators that are knowledgeable

the University of Pretoria's Med (Educational Psychology)

programme each year

classrooms to work in, as well as desks, chairs and stationery

women that cook food at school, thus providing nutrition

finds support from teachers, friends and family

he feels he has an important role to fulfil in the community

awareness of HIV/AIDS, through acknowledging the

children who have HIV/AIDS, as well as the teenagers

who have to look after themselves

financial situation

HIV/AIDS barriers in the society as well as in own life

lack of electricity and water resources

lack of resources for research, like internet and a

well-resourced library

feels the community may have a misconception of who he is

experiences himself in isolation from the community and

others

he feels the community sees him in a negative light

removing himself from the community

struggles with social relations

Figure 4. Quadrant map of a 16-year old boy resulting from combined measurement

will give her information on bursaries in the career fields that interest her.

\section{Discussion}

Quadrant mapping yield useful descriptive data for learner focused career counseling. It would also appear that postmodern, as well as existing and adapted, career counseling measures are useful to glean information on risk factors and protective resources for quadrant maps. Further studies may indicate notable differences (if any) in the complexity of the information on quadrant maps, which may vary according to particular modes of assessment - regrettably, the sample size in this study is too limited for such inferences. However, this study does not propose quadrant maps as a career counseling measure on their own. As the students could present measured risk factors and protective resources in quadrant maps, these can rather be seen as a descriptive product of measured risk factors and protective resources. In this way quadrant maps would also appear to have value in structuring the analysis and interpretation of assessment information.

In terms of resilience as a career counseling endeavour, students used quadrant maps to indicate to youth how buffers could be used to address risk - potentially strengthening the possibility of future resilience. In this way, quadrant maps seem to be useful in directing career counseling discussions to indicate strategies which may guide resilient choices. Youth's awareness of existing resources, as well as prevailing needs, may arguably result in them selecting available resources to ad- dress challenges. Notably, the emphasis here falls on the possibility of using quadrant maps in career counseling to facilitate future resilience. Whether or not youth used quadrant map-related strategies falls outside of the scope of this inquiry - thus measuring the connection between quadrant maps in career counseling and future resilience remains an illusive assumption. What did become evident from this study is that quadrant maps can be used during career counseling to illustrate the way in which assets can be used to mediate barriers. Future studies should investigate the extent to which the use of quadrant mapping during career counseling may in fact enable the use of protective resources to address risk factors and flourish in preferred endeavors.

Students were able to use varied approaches to identify risk factors and protective resources during career counseling assessment. It is possible to culturally adapt existing measures for use in this resource-scarce environment with a cross-cultural population (Carter et al., 2005). The adapted measures and the postmodern measures enabled students to engage with youth who differed from them (the students) in terms of race, language, socioeconomic status, geographical variables, and educational level and, in some instances, gender and religion. Therefore, it would seem that quadrant mapping is useful for cross-cultural career counseling. This finding echoes that of other studies, which also indicate the utility of postmodern (Maree et al., 2001) and culturally tailored (Gierl, 2007) measures in cross-cultural career counseling. 
Like other narrative career counseling techniques (Cochran, 2007), quadrant maps seem useful in group-based and school-based career counseling. In this regard, the youth in this study seemed to benefit from the career counselors (students) facilitating a group-based process involving the interpretation of quadrant maps. This finding is significant in the light of the large numbers of vulnerable youth in South Africa who need career counseling, on the one hand, and the small number of trained professionals on the other. In order to generalise this finding, additional inquiry on quadrant mapping in other school settings with other groups of counselors and youths is recommended. In addition it may be constructive to determine whether teachers could use quadrant mapping to facilitate career discussions in the classroom.

Areas that also warrant further investigation are to establish how the youth experience the use of quadrant maps in career counseling and, longitudinally, to determine the extent to which youth apply the notion of accessing identified resources to address adversity.

\section{Conclusion}

The quadrant map has utility for career counselors assisting clients to design lives in which available resources can be used to address adversity. Consequently, it can be argued that quadrant maps have the potential to enable resilience in clients in career counseling. In particular, for post-colonial countries with emerging economies like South Africa, quadrant maps have cross-cultural career counseling value as they allow for counselor-client meaning-making across language, culture and socioeconomic diversity. Whether or not quadrant maps have life-design value (as a way of enabling vulnerable individuals to confront continued adversity in order to live happily) remains an unanswered research question for the future. However, quadrant maps can make youth aware of existing resources even in the presence of immense scarcity, as is evident from this student's reflection:

One of the boys said he realised that he is just like this seed we are planting, he needs water to grow, from his family and support network but also from himself (his gifts and assets). He also spoke about his "sun"' and "ground" that will enable him to grow.

\section{References}

Adair, J. G., Puhan, B. N., \& Vohra, N. (1993). Indiginization of psychology: Empirical assessment of progress in Indian research. International Journal of Psychology, 28, 149-169.

Amon, J. J. (2002). Preventing HIV infections in children and adolescents in sub-Saharan Africa through integrated care and support activities: A review of the literature. African Journal of Aids Research, 1(2), 143-149.

Bachorowski. J. A., \& Owen, M. J. (2001). Not all laughs are alike: Voiced but not unvoiced laughter readily elicits positive affect. Psychological Science, 12, 252-257.

Backette-Milburn, K., \& McKie, L. (1999). A critical appraisal of the draw and write technique. Health Education Research, 14(3), 387-398.

Bender, C. J. G. (2008). Exploring conceptual models for community engagement at higher education institutions in South Africa. Perspectives in Education, 26(1), 81-95.

Bender, C. J. G., Daniels, P., Lazarus, J., Naude, L., \& Sattar, K. (2006). Service-learning in the curriculum: A resource for higher education institutions. Pretoria, South Africa: Council on Higher Education/ Higher Education Quality Committee/JET Education services.

Bennell, P. (2005). The impact of the AIDS epidemic on teachers in sub-Saharan Africa. Journal of Development Studies, 41(3), 440-466.

Bennell, P., Hyde, K., \& Swainson, N. (2002). The impact of the HIVIAIDS epidemic on the education sector in sub-Saharan Africa: A synthesis of findings and recommendations of three country studies. Brighton, England: University of Sussex Institute of Education, Centre for International Education.

Bonanno, G. A. (2004). Loss, trauma, and human resilience: Have we underestimated the human capacity to thrive after extremely aversive events? American Psychologist, 59(1), 20-28.

Booysen, F., \& Arntz, T. (2002). Children of the storm: HIV/AIDS and children in South Africa. Social Dynamics, 28(1), 170-192.

Brandt, A. (2005). Translation, cross-cultural adaptation, and content validation of the QUEST. Technology and Disability, 17(4), 205-216.

Braun, V., \& Clarke, V. (2006). Using thematic analysis in psychology. Qualitative Research in Psychology, 3(2), 77-101.

Bray, R. (2003). Predicting the social consequences of orphanhood in South Africa. African Journal of AIDS Research, 2(1), 39-55.

Brookes, H., Shisana, O., \& Richter, L. (2004). The national household HIV prevalence and risk survey of South African children. Cape Town, South Africa: Human Sciences research Council.

Carter, J. A., Lees, J. A., Murira, G. M., Gona, J. G., Neville, B. G. R., \& Newton, C. R. J. C. (2005). Issues in the development of cross-cultural assessments of speech and language for children. International Journal of Language and Communication Disorders, 40(4), 385-401.

Carver, C. S., \& Scheier, M. F. (2005). Optimism. In C. R. Snyder \& S. J. Lopez (Eds.), Handbook of positive psychology (pp. 231-243). New York, NY: Oxford University Press.

Chope, R.C., \& Consoli, A.J. (2007). A storied appraoch to multicultural career counseling. In K. Maree (Ed.), Shaping the story: A guide to facilitating narrative counseling ( $\mathrm{pp}$. 87-100). Pretoria, South Africa: Van Schaik.

Cluver, L., \& Gardner, F. (2006). The psychological well-being of children orphaned by AIDS in Cape Town, South Africa. Annals of General Psychiatry, 5(8).

Cluver, L., \& Gardner, F. (2007). Risk and protective factors for psychological well-being of children orphaned by AIDS in Cape Town: A qualitative study of children and caregivers' perspectives. AIDS Care, 19(3), 318-325.

Cluver, L., Gardner, F., \& Operario, D. (2007). Psychological distress amongst AIDS-orphaned children in urban South Africa. Journal of Child Psychiatry and Psychology, 48(8), 755-763.

Cochran, L. (2007). The promise of narrative career counseling. In K. Maree (Ed.), Shaping the story: A guide to facilitating narrative counseling (pp. 7-19). Pretoria, South Africa: Van Schaik.

Ebersöhn, L., \& Eloff, I. (2006). Life skills and assets (2nd ed.). Pretoria, South Africa: Van Schaik. 
Ebersöhn, L. (2006). FLY students transferring skills to youth: Career and learning development (Research report for M\&SS Trust). Pretoria, South Africa: University of Pretoria.

Ebersöhn, L. (2008). Children's resilience as assets for safe schools. Journal of Psychology in Africa, 18(1), 11-18.

Ebersöhn, L. (2007). Utilising reminiscences: Constructing boxes of memories to tell stories for life choices. In K. Maree (Ed.), Shaping the story: A guide to facilitating narrative career counseling (pp. 152-162). Pretoria, South Africa: Van Schaik.

Fredrickson, B. L., \& Losada, M. F. (2005). Positive affect and the complex dynamics of human flourishing. American Psychologist, 60(7), 678-686.

Gierl, M. J. (2007). Book review: Adapting educational and psychological tests for cross-cultural assessment. Applied Psychological Measurement, 31(1), 74-78.

Hartung, P.J. (2007). Career construction: Principles and practice. In K. Maree (Ed.), Shaping the story: A guide to facilitating narrative counseling (pp.103-120). Pretoria, South Africa: Van Schaik.

Keyes, C. L. M. (2007). Promoting and protecting mental health as flourishing: A complementary strategy for improving national mental health. American Psychologist, 62(2), 95-108.

Lopez, S. J., Magyar-Moe, J. L., Petersen, S. E., Ryder, J. A., Krieshok, T. S., O’Byrne, K. K., Lichtenberg, J. W., \& Fry, N. A. (2006). Counseling psychology's focus on positive aspects of human functioning. The Counseling Psychologist, 34(2), 205-227.

Maree, J. G., Bester, S. E., Lubbe, C., \& Beck, C. (2001). Post-modern career counseling to a gifted black youth: A case study. Gifted Education International, 15(3), 324-338.

Mauthner, M. (1997). Methodological aspects of collecting data from children: Lessons from three research projects. Children and Society, 11, 16-28.

McMahon, M., \& Patton, W. (2002). Using qualitative assessment in career counseling. International Journal for Educational and Vocational Guidance, 2(1), 51-66.

O’ Dougherty Wright, M., \& Masten, A. (2006). Resilience processes in development. In S. Goldstein \& R. B. Brooks (Eds.), Handbook of resilience in children (pp. 17-37). New York, NY: Springer.

Patton, W. (2007). Theoretical underpinnings and practical application of constructivist approaches to career counseling. In K. Maree (Ed.), Shaping the story: A guide to facilitating narrative counseling (pp.121-133). Pretoria, South Africa: Van Schaik.

Savickas, M. L. (2003). Advancing the career counseling profession: Objectives and strategies for the next decade. Career Development Quarterly, 52, 87-95.

Savickas, M. L. (2007). Internationalisation of counseling psychology: Constructing cross-national consensus and collaboration. Applied Psychology: An International Review, 5691, 182-188.

Schreuder, A. M. G., \& Coetzee M. (2006). Careers: An organizational perspective (3rd ed.). Cape Town, South Africa: Juta and Co.

Seale, C. (2000). The quality of qualitative research. London, England: Sage.

Smith, E. J. (2006). The strength-based counseling model. The Counseling Psychologist, 34(1), 13-79.
Stake, R. E. (1995). The art of case study research. Thousand Oaks, CA: Sage.

Stead, G. B., \& Watson, M. B. (1998). Career research in Africa: Challenges for the future. Journal of Vocational Behavior, 52, 289-299.

Thrift, E., \& Amundson, N. (2005). Hermeneutic-narrative approach to career counseling: An alternative to postmodernism. Perspectives in Education, 23(2), 9-20.

Watson, M. B., \& MacMahon, M. (2004). Postmodern (narrative) career counseling and education. Perspectives in Education, 22, 169-170.

\section{Endnotes}

${ }^{1}$ Vulnerable youth refers to adolescents experiencing adversity because of risk factors in themselves or their environments (Amon, 2002)

${ }^{2}$ I define a quadrant map as follows: a quadrant map visually depicts both risk factors and protective resources in individuals' intrapersonal systems, as well as their environments.

${ }^{3}$ Academic service learning engages students in activities in which both the community and student(-s) are simultaneously the primary beneficiaries (Bender, Daniels, Lazarus, Naude, \& Sattar, 2006)

${ }^{4}$ Diversity with regard to gender, religion and language is increasingly evident in the student base.

${ }^{5}$ Tshepo is a pseudonym.

${ }^{6}$ The student developed a questionnaire to explore interest. She made use of easily accessible language, and included isiZulu synonyms for core concepts.

${ }^{7}$ This activity is based on vocational card sorting which the student adapted to include isiZulu words and simplified by selecting a small number of vocations.

${ }^{8}$ The student used an existing measure to explore personality. She adapted the questionnaire to include isiZulu translations of core concepts.

${ }^{9}$ Drawings include the Kinaesthetic Family Drawing, Draw a Person, as well as drawings focused on a past, present and future depictions.

${ }^{10}$ Londiwe is a pseudonym. 